\title{
A Framework to Study Farmers Decisions on Adoption of Agromet Advisories Services for Risk Management: Insights from Theory of Planned Behavior
}

\author{
Jagriti Rohit, C.N. Anshida Beevi \\ ICAR- Central Research Institute for Dryland Agriculture, \\ Santoshnagar, Hyderabad-500 059, Telangana, India.
}

Received: September 2021

Accepted: February 2022

\begin{abstract}
Background: Climate change is emerging as a major threat on agriculture, food security and livelihood of millions of people in many places of the world. Agromet advisories services is such a climate resilient technology which provides the valuable information about all agricultural operations from land preparation sowing to harvest based on weather forecasting. There have been plenty of studies investigating farmers' decision to adopt an innovation but a lot of more segregated studies exist, highlighting the importance of individual factors affecting adoption. Most of the theoretical models on adoption of innovation have tended to present discipline guided explanations to the adoption decision, although adoption is subject to a combination of social, economic, psychological, as well as cultural factors.

Methods: The aim of the paper is to present a framework to study farmer's decision with respect to adoption of AAS. Under aegis of NICRA, Agromet Advisories are provided to the farmers through its 121 Krishi Vigyan Kendra located in India. The agromet advsiories along with weather data gives crop specific recommendations. Generally, these advisories ae given to farmers two times in a week. The developed framework will be used to study their intention to adopt these AAS. Extensive review of literature on the adoption of innovation in agriculture that was based on TPB or theory of reasoned change (TRA) was carried out.

Result: Various factors were taken into consideration like the demographic variables, socio- psychological constructs for explaining the adoption decisions. The framework developed for the study is an extended version of ajzen's Theory of Planned Behavior (TPB). In addition to the traditional construct i.e intention, perceived behavioural control and subjective norms, perceived usefulness was added to the extended version of TPB to study the adoption of Agromet Advisories Services (AAS). The framework will help the academician, policy makers and other stakeholder to develop different perspectives of farmer's decision making in adoption of AAS.
\end{abstract}

Key words: Agromet advisories, services (AAS) Attitude, Construct, Subjective norms, Theory of planned behavior (TPB), Attitude toward the behavior (ATT), Perceived behavioral control (PBC), Subjective norm (SN).

\section{INTRODUCTION}

Climate change is emerging as a major threat on agriculture, food security and livelihood of millions of people in many places of the world (IPCC, 2014). It is necessary to manage the risk associated with climate variability for sustainable food and agriculture system. Farming communities across the continents have showed the ability to adapt to the vagaries of nature since ages but increasingly erratic climate variability and the rapid pace of other drivers of change are overwhelming indigenous knowledge and traditional coping practices. Agromet advisories services is such a climate resilient technology which provides the valuable information about all agricultural operations from land preparation sowing to harvest based on weather forecasting. The emerging ability to provide timely, skillful weather forecasts offers the potential to reduce human vulnerability to weather vagaries (Hansen, 2002). Therefore, any forecast on weather would have tremendous benefits in terms of ex ante management of the negative impacts of vagaries of weather. The major objective of AAS was to help the farmers in capitalizing prevailing weather conditions in order to optimize the resource use and to minimize the loss due to harsh/ aberrant weather conditions (Venkataraman, 2004). Hence, adoption of agromet advisories by farmers has major implication in mitigating the ill effect of climate change.

There have been plenty of studies investigating farmers' decision to adopt an innovation but a lot more segregated studies exist, highlighting the importance of individual factors affecting adoption. Most of the theoretical models on adoption of innovation have tended to present discipline guided explanations to the adoption decision, although adoption is subject to a combination of social, economic,

\footnotetext{
*Corresponding author's E-mail: jags.rohit@gmail.com
} 
psychological, as well as cultural factors (Boahene et al., 1999; Edwards-Jones, 2006). earlier works were mainly focused on farmers' socioeconomic and structural factors, more recent research has addressed farmers' attitudes and motivations (Li et al., 2019). It has been observed in recent past that there has been increasing interest in scientific fraternity to study adoption through socio-psychological methods and this interest has been induced by a growing discontent with the use of classic variables in adoption studies. From a theoretical point of view, there is a gap in the literature providing a formal integration of sociologic, economic and psychological variables in the relevant models (Edwards-Jones, 2006). The present paper is an attempt to arrive at a conceptual framework based on Theory of planned behavior (TPB) to study farmers' decisions on adoption of weather based advisories/ agromet advisories. The framework is in line with work of Wauters and Mathijs (2013) and Borges et al (2015).

\section{MATERIALS AND METHODS}

The aim of the paper is to present a framework to study farmer's decision with respect to adoption of AAS. Under aegis of NICRA, Agromet Advisories are provided to the farmers through its 121 Krishi Vigyan Kendra located in India. They are getting agromet advisories services in form of mesaages through the KVK and also rom m-kisan portal. The agromet advsiories along with weather data gives crop specific recommendations. Generally, these advisories ae given to farmers two times in a week. The developed framework will be used to study their intention to adopt these AAS. Extensive review of literature on the adoption of innovation in agriculture that was based on TPB or theory of reasoned change (TRA) was carried out. The review was done with the twin objectives: firstly, to identify variables used to understand farmers' decisions on adoption of an innovation; second to categorize the variables in groups. After identifying and classifying the variables, a framework was developed to integrate the variables in framework, using the insights from TPB.

\section{RESULTS AND DISCUSSION Conceptual framework and hypothesis}

Ajzen's Theory of Planned Behavior (TPB) is a sociopsychological model which postulates that a person's/ decision making unit intention to enact a given behavior is the strongest predictor of that behavior (Fig 1). Through the conceptual extension of this theoretical model, a model for farmers' decision-making in the adoption of agromet advisories services has been constructed in this paper. This model allows us to incorporate psychological factors and external factors into the same analytical framework.

TPB consists of three constructs, the first construct is Attitude which is define as the degree to which a person evaluate or appraise the behavior in question to favorable (Crano and Prislin, 2006) or unfavorable captured in a dimension of pleasant or not pleasant, good or bad, harmful or beneficial like or dislike (Ajzen, 2001). According to Rosenberg (1960), the person's attitude toward the object will mediate all responses to that object. Many researchers have found the strength of relationship of attitude to explain behavior (Ajzen and Driver, 1992; Crano and Prislin, 2006). Subjective Norms (SN) is the second construct, explained as different social references that exert influence or social pressure to perform a behavior (Dulany, 1968). TPB suggested that one can form a belief based on what other people (important others) expect us to do or based on the observation on the action of the important others. People will possess favorable attitude on certain object, but if the important others pressures not to do it, people will then have negative attitude towards the behavior (Cialdini, Reno and Kallgren, 1990; Fishbein and Ajzen, 2010). The Perceived behavioral control indicates the perceived belief of easiness or difficultness in performing behavior. It is also a reflection of beliefs of the availability of resources and opportunities in order to perform the behavior (Ajzen, 1991; Taylor and Todd, 1995). The theory of planned behavior (TPB) is an extension of Theory of reasoned action (TRA) with an additional constructs called perceived behavioral control.

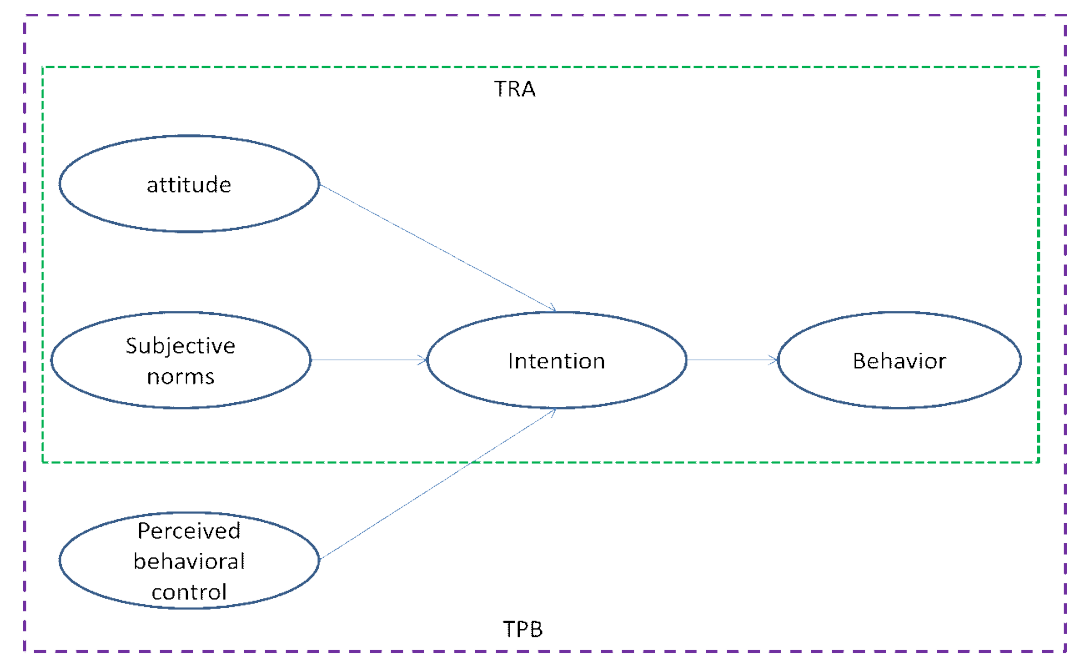

Fig 1: Theory of Planned Behavior (TPB) and Theory of Reasoned Action (TRA) Source: Adapted from Ajzen 1991. 
Perceived Behavioral Control (PBC) is important in explaining people's behavior especially when they do not have whole control due to situational factor (Chiou, 1998). Therefore the Theory of Planned Behavior (TPB) has been proposed to remedy this problem which was not addressed in the Theory of Reasoned Action (TRA) earlier (Ajzen, 1985).

Where,

$$
\mathrm{BI}=\mathrm{Aact}+\mathrm{SN}+\mathrm{PBC}
$$

$\mathrm{BI}=$ Intention.

Aact $=$ Attitude.

$\mathrm{PBC}=$ Perceived behavioral control.

The theory of planned behavior is, in principle, open to the inclusion of additional predictors if it can be shown that they capture a significant proportion of the variance in intention or behavior after the theory's current variables have been taken into account" (Ajzen, 1991). Hence, it can be modified according to the situation and context. In the present framework, perceived usefulness of the innovation is added to study (Fig 2). Perceived usefulness is defined as the extent to which a person believed that the agromet advisories were capable of being used advantageously and provided expected outcomes (Davis, 1989).

$$
\mathrm{BI}=\mathrm{Aact}+\mathrm{SN}+\mathrm{PBC}+\mathrm{PU}
$$

Where,

$\mathrm{BI}=$ Intention.

Aact $=$ Attitude.

$\mathrm{PBC}=$ Perceived Behavioral Control.

$\mathrm{PU}=$ Perceived usefulness.

The following are the hypothesis for the present study

Hypothesis 1. Attitude affects behavioral intention.

Hypothesis 2. Subjective norm affects behavioral intention.

Hypothesis 3. Perceived behavioral control affects behavioral intention.

Hypothesis 4. Perceived usefulness affects behavioral intention Hypothesis 5. Behavioral intention affects behavior.

\section{Hypothesis 1}

Attitude affects behavioral intention. Attitude here refers to farmers' view on AAS.

Attitude has been identified as a cause of intention. Attitude is defined as "the degree to which a person has a favorable or unfavorable evaluation or appraisal of the behavior in question" (Azjen 1991). In other words, attitude reflects feeling of favorableness or unfavorableness to perform a certain behavior (Taylor and Todd, 1995). Allport 1967, considered attitude as a state of mind capable of exercising a direct or indirect influence on the individual's response to all objects and situations with which it is associated. According to Fishbein and Ajzen 2010, attitude regards some social aspects of the individual's world as a person, a physical object, a behavior, or a policy. This it is hypothesized that behavioral intention is a function (also) of attitude. Thus, it can be said that Based on what is described; behavioral intention can be predicted by analyzing the attitude towards that intention. To measure attitude, seven set of questions on 5 point continumm was prepared. It included their attitudes towards AAS usefulness, worth, reliability, ease of use and good idea.

\section{Hypothesis 2}

Subjective norm affects behavioral intention. Subjective norm, in this study is defined as social circle's views on agromet adviosries services. Subjective norm is defined as "the person's perception that most people who are important to him or her think he/she should or should not perform the behavior in question" (Abbasi et al, 2013). Therefore, it can be believed that subjective has influence on behavioral intention. According to Trafimow and Fishbein 1994, the subjective norm expresses the result of a series of pressures exerted by some individuals that can influence a person's behavior. In general, the subjective norm seems to play a fundamental role in the formation of people's behavioral



Fig 2: An Extended Theory of Planned Behavior. Source: Authors. 
intention with a positive or negative ascendancy that induces each individual to perform certain actions and avoid others. Based on the arguments proposed so far, this analysis intended to check whether: Subjective norm affects behavioral intention. In the schedule developed, questions were included to assess the farmers perception about their peers and influencers adoption of AAS in last 12 months. Renita and Anindita 2017 also concluded in their study that attitudes, subjective norms and perceived behavioral control have positive influences for farmers' intention towards climate change adaptation.

\section{Hypothesis 3}

Perceived behavioral control affects behavioral intention. In this study, Perceived behavioral control refers to the farmers ability to adopt and implement AAS. Perceived behavioral control is another such variable which considered capable of affecting an individual's behavioral intention. Perceived Behavioral Control (PBC) refers to an individual's confidence in his/her abilities to correctly perform the behavior in question (Ajzen, 1991; Bandura, 1986). Farmers who have high confidence on their agriculture practice has had a high perception also to cope the risks from climate change (Roesch-mcnally, 2016). People have a belief that they can perform a particular behavior when they think they have the resources and opportunities to perfect it and think they can freely make the decision to use those resources. Trust that people places in their ability to perform a future action, strongly influence the behavioral intention. Nguyen, N. and Drakou 2021 in their study indicate that farmers' intention to adopt sustainable agricultural practices was influenced by their perception of social pressure and their abilities to perform sustainable agriculture. Farmers' climate change perception also significantly influenced their behavioral determinants. Researches in climate change adaptation has shown that Perceived behavioral control is the most significant factor contributing to intention to adopt sustainable agricultural behavior (Jiang et al., 2018).

\section{Hypothesis 4}

Perceived usefulness affects behavioral intention. Perceived usefulness in this framework refers the degree to adoption of AAS in farming operation will enhance the production and profitability along with reducing the risk involved due to uncertain weather conditions. Davis 1989 pointed out that individuals tend to adopt certain behavior on the basis of how much the product (good or service) helps them to perform an activity; whereas the scholar defines perceived usefulness as "the degree to which a person believes that using a particular system would enhance his or her job performance". It is one of the major factors directly influencing the behavioral intention to use a technology (Cigdem and Topcu, 2015). In other terms, perceived usefulness is conceived as a determinant of an individual's intention to perform a future behavior and hence, considered for this study.

\section{Hypothesis 5}

Behavioral intention affects behavior. Applying the TPB for this case study, behavioral intention refers to intention to adopt agromet advisories services while doing farming operations. Behavioral intention is defined as the degree to which a person has formulated conscious plans to perform or not to perform some specified future behavior (Warshaw and Davis, 1985). According to Triandis and Brislin 1980, an individual's behavioral intentions can be seen as selfinstructions that enable performing certain behaviors or obtaining particular outcomes. Behavioral intention is said to be a variable dependent on many others (such as attitude, subjective norm, perceived behavioral control, perceived usefulness and so forth); on the other hand, it is equally true that it can also be seen as a variable capable of influencing behavior, that is, actions actually taken (Webb and Sheeran, 2006). Behavior intention appears to be a strong antecedent of the actual behavior i.e adoption of AAS. In this model, farmers demographic profile, personality and communication variable will also be considered.

\section{CONCLUSION}

Agriculture is unique, whose output is largely dependent on weather conditions. The degree of success of agriculture production and its economics is determined to a significant extent by how well weather conditions corresponding to the optimal requirements of the crop are best exploited to raise the crops. Adoption of real time contingencies in crop management based on weather forecasts can minimize crop losses. Various researches have shown that Farmers' intention to adapt was mostly affected by perceived behavioral control factors, followed by attitude and subjective norms (Arunrat et al., 2017). Hence, to study the adoption of AAS, the present framework incorporates variables from theory of planned behavior to study the farmer's decision to adopt agromet advisory services. Adoption decision depends on complex factors. This study integrates both the psychological constructs and the background factors of the farmers. The framework incorporates perceived usefulness as an extension to the theory of planned behavior. The study will help the academician, policy makers and other stakeholder to develop different perspectives of farmer's decision making.

\section{REFERENCES}

Abbasi, M.S., Shah, F., Doudpota, S.M., Channa, N. and Kandhro, S. (2013). Theories and models of technology acceptance behaviour: A critical review of literature. Sindh University Research Journal-SURJ (Science Series). 45(1): 163-170.

Ajzen, I. (1991). The theory of planned behavior. Organizational behavior and human decision processes. 50: 179-211.

Ajzen, I. (1985). From Intentions to Actions: A Theory of Planned Behavior. In Action Control; [KuhlJürgen, J., Beckmann, J., Eds.]; Springer: Berlin, German; ISBN 978-3-642-69746-3. pp. 11-39. 
Ajzen, I. (2001). Nature and operations of attitudes. Annual Review of Psychology. 52: 27-58.

Ajzen, I. and Driver, B.L. (1992). Application of the theory of planned behaviour to leisure choice. Journal of Leisure Research. 24(3): 185-204.

Allport, G.W. (1967). Attitudes in Attitude Theory and Measurement; John Willey Sons: New York, NY, USA, ISBN 978-0471 260554.

Arunrat, N., Wang, C., Pumijumnong, N., Sereenonchai, S. and Cai, W. (2017). Farmers' intention and decision to adapt to climate change: A case study in the Yom and Nan basins, Phichit province of Thailand. Journal of Cleaner Production. 143: 672-685.

Bandura, A. (1986). Social foundations of thought and action. Englewood Cliffs, NJ.

Boahene, K., Snijders, T.A., Folmer, H. (1999). An integrated socioeconomic analysis of innovation adoption: The case of hybrid cocoa in Ghana. J. Policy Model. 21: 167-184.

Borges, J.A.R., Foletto, L. and Xavier, V.T. (2015). An interdisciplinary framework to study farmers decisions on adoption of innovation: Insights from Expected Utility Theory and Theory of Planned Behavior. African Journal of Agricultural Research. 10(29): 2814-2825.

Chiou, J.S. (1998). The Effects of Attitude, Subjective Norm and Perceived Behavioral Control on Consumers' Purchase Intentions: The Moderating Effects of Product Knowledge and Attention to Social Comparison Information. Proc. Natl. Sci. Counc. ROC (C). 9(2): 298-308.

Cialdini, R.B., Reno, R.R. and Kallgren, C.A. (1990). A focus theory of normative conduct: Recycling the concept of norms to reduce littering in public places. Journal of Personality and Social Psychology. 58: 1015-1026.

Cigdem, H. and Topcu, A. (2015). Predictors of instructors' behavioral intention to use learning management system: A Turkish vocational college example. Computers in Human Behavior. 52: 22-28.

Crano, W.D. and Prislin, R. (2006). Attitudes and Persuasion. Annual Review of Psychology. 57(1): 345-374.

Davis, F.D. (1989). Perceived usefulness, perceived ease of use and user acceptance of information technology. MIS $Q$. 13: 319-340.

Dulany, D.E. (1968). Awareness, Rules and Propositional Control: A Confrontation with S-R Behavior Theory. New York: Prentice Hall.

Edwards-Jones, G. (2006). Modelling farmer decision-making: Concepts, progress and challenges. Animal Science. 82(6): 783-790.

Fishbein, M. and Ajzen, I. (2010). Predicting and Changing Behavior: The Reasoned Action Approach. Psychology Press, New York.

Fishbein, M. and Ajzen, I. (2010). Predicting and changing behavior: The reasoned action approach. New York: Psychology Press (Taylor and Francis).

Hansen, J.W. (2002). Applying seasonal climate prediction to agricul-tural production. Agric. Syst. 74(3): 305-307.
IPCC (Intergovernmental Panel on Climate Change). (2014). Climate Change 2014, Impacts, Adaptation and Vulnerability, Part A: Global and Sectoral Aspects, Working Group II Contribution to the Fifth Assessment Report of the Intergovernmental Panel on Climate Change.

Jiang, L., Zhang, J., Wang, H.H., Zhang, L. and He, K. (2018). The impact of psychological factors on farmers' intentions to reuse agricultural biomass waste for carbon emission abatement. Journal of Cleaner Production. 189: 797-804.

Li, P., Chen, Y., Hu, W., Li, X., Yu, Z. and Liu, Y. (2019). Possibilities and requirements for introducing agri-environment measures in land consolidation projects in China, evidence from ecosystem services and farmers' attitudes. Science of the Total Environment. 650: 3145-3155.

Nguyen, N. and Drakou, E.G. (2021). Farmers intention to adopt sustainable agriculture hinges on climate awareness: The case of Vietnamese coffee. Journal of Cleaner Production. 303: 126828.

Renita, D. and Anindita, R. (2017). Farmer's intention on climate change adaptation. Agricultural Socio-Economics Journal. 17(3): 105-111.

Roesch-Mcnally, G.E. (2016). Agricultural transformations: Climate change adaptation and farmer decision making, Graduate Theses and Dissertations. p. Paper 15051.

Rosenberg, M.J. and Hovland, C.I. (1960). Cognitive, Affective and Behavioral Components of Attitudes. In: Attitude Organization and Change: [C.I. Hovland and M.J. Rosenberg (Eds.)], An Analysis of Consistency Among Attitude Components. New Haven, CT: Yale University Press. pp. 1-14.

Taylor, S. and Todd, P.A. (1995). Understanding information technology usage: $A$ test of competing models. Information Systems Research. 6(2): 144-76.

Trafimow, D. and Fishbein, M. (1994). The moderating effect of behavior type on the subjective norm-behavior relationship. The Journal of Social Psychology. 134(6): 755-763.

Triandis, H.C. and Brislin, R.W (1980). Handbook of Cross-CulturalPsychology; Allyn and Bacon: Boston, MA, USA; ISBN 978-0-20-5065011.

Venkataraman, S. (2004). Climatic characterization of crop productivity and input-needs for agrometeorological advisory services. Journal of Agrometeorology. 6(1): 98-105.

Warshaw, P. and Davis, F. (1985). Disentangling behavioral intention and behavioral expectation. Journal of Experimental Social Psychology. 21: 213-228. doi: 10.1016/00221031(85)90017-4.

Wauters, E. and Mathijs, E. (2013). An investigation into the sociopsychological determinants of farmers' conservation decisions: Method and implications for policy, extension and research. The Journal of Agricultural Education and Extension. 19(1): 53-72.

Webb, T.L. and Sheeran, P. (2006). Does changing behavioral intentions engender behavior change? A meta-analysis of the experimental evidence. Psychological Bulletin. 132(2): 249-268. 